\title{
An Optimal Treatment Control of TB-HIV Coinfection
}

\author{
Fatmawati $^{1}$ and Hengki Tasman ${ }^{2}$ \\ ${ }^{1}$ Departemen Matematika, Fakultas Sains dan Teknologi, Universitas Airlangga, Surabaya 60115, Indonesia \\ ${ }^{2}$ Departemen Matematika, Fakultas Matematika dan Ilmu Pengetahuan Alam, Universitas Indonesia, Depok 16424, Indonesia
}

Correspondence should be addressed to Fatmawati; fatma47unair@gmail.com

Received 6 January 2016; Revised 5 March 2016; Accepted 7 March 2016

Academic Editor: Ram U. Verma

Copyright (C) 2016 Fatmawati and H. Tasman. This is an open access article distributed under the Creative Commons Attribution License, which permits unrestricted use, distribution, and reproduction in any medium, provided the original work is properly cited.

\begin{abstract}
An optimal control on the treatment of the transmission of tuberculosis-HIV coinfection model is proposed in this paper. We use two treatments, that is, anti-TB and antiretroviral, to control the spread of TB and HIV infections, respectively. We first present an uncontrolled TB-HIV coinfection model. The model exhibits four equilibria, namely, the disease-free, the HIV-free, the TB-free, and the coinfection equilibria. We further obtain two basic reproduction ratios corresponding to TB and HIV infections. These ratios determine the existence and stability of the equilibria of the model. The optimal control theory is then derived analytically by applying the Pontryagin Maximum Principle. The optimality system is performed numerically to illustrate the effectiveness of the treatments.
\end{abstract}

\section{Introduction}

Tuberculosis (TB) is an infectious disease caused by bacteria Mycobacterium tuberculosis that most often attack the lungs. The bacteria are spread through air from one person to another when the people with active TB cough, sneeze, speak, or sing. People nearby may breathe in these bacteria and become infected. According to the World Health Organization (WHO), one-third of the world's population is infected with TB [1]. In 2013, 9 million people around the world became sick with TB disease and around 1.5 million TBrelated deaths worldwide were reported. TB is the most common opportunistic disease that affects people infected with HIV [2].

HIV stands for human immunodeficiency virus that can lead to acquired immunodeficiency syndrome (AIDS). HIV can be transmitted via the exchange of a variety of body fluids from infected individuals, such as blood, breast milk, semen, and vaginal secretions. There is no cure for HIV infection. However, effective treatment with antiretroviral (ARV) drugs can control the virus so that people with HIV can enjoy healthy and productive lives [3]. As reported in WHO fact sheet (2013), at least one-third of the 34 million people living with HIV worldwide are infected with TB. HIV and TB form a lethal combination, each speeding the other's progress. TB is one of the leading causes of death among people living with HIV. Almost $25 \%$ of deaths among people with HIV are due to TB [1]. Therefore, an effective strategy is needed to control the transmission of TB-HIV coinfection in the population.

Mathematical models provide an important tool in understanding the spread and control of TB-HIV coinfection diseases. The dynamics of the transmission of TB-HIV coinfection model have been studied by many researchers [4-7]. Gakkhar and Chavda [4] formulated the dynamics of TB-HIV coinfection model with the population divided into four subclasses: the susceptible class, the TB infective class, the HIV infective class, and the TB-HIV coinfection class. They found the basic reproduction number for each of the diseases and checked the stability results for the equilibrium points. Naresh et al. [5] proposed a model to study the effect of tuberculosis on the transmission dynamics of HIV in a logistically growing human population. Roeger et al. [6] focus on the joint dynamics of HIV and TB in a pseudocompetitive environment, at the population level. Sharomi et al. [7] discussed the synergistic interaction between HIV and Mycobacterium tuberculosis using a deterministic model, with many of the essential biological and epidemiological features of the two infections. 


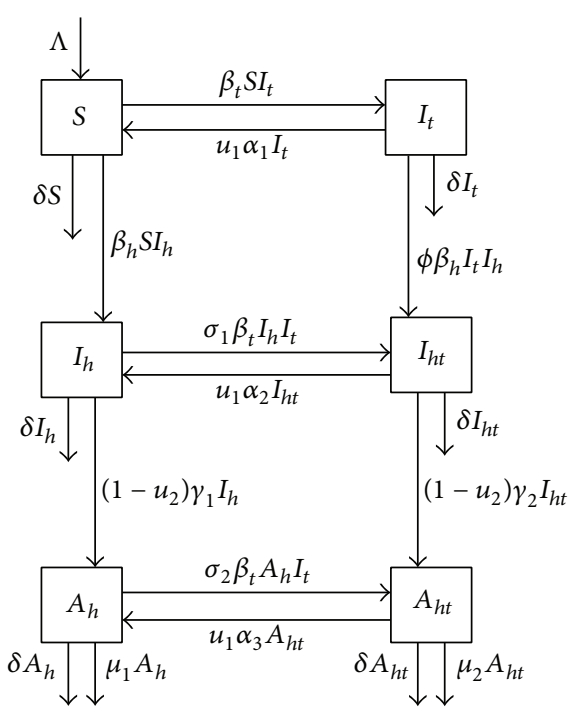

FIgURE 1: TB-HIV coinfection transmission diagram.

In this paper, mathematical model with an optimal control on the treatment of TB-HIV coinfection is proposed. The optimal control strategies have been applied to the studies on epidemiological models such as HIV, TB, Hepatitis C, Malaria, coinfection Malaria-Cholera, and HIV-Malaria diseases dynamics [8-16]. Very few studies have been applied in the area of optimal control theory to TB-HIV coinfection models. Recently, Agusto and Adekunle [17] have used optimal control strategies associated with treating symptomatic individuals with $\mathrm{TB}$ using the two-strain TB-HIV/AIDS transmission model. The aim of this study is to analyze the effect of two treatment scenarios, that is, anti-TB and ARV, to control the spread of TB-HIV coinfection diseases.

The organization of this paper is as follows. In Section 2, we derive a model of tuberculosis-HIV coinfection transmission with controls on anti-TB and ARV treatment. The model is analyzed in Section 3. In Section 4, we show the numerical simulations to illustrate the effectiveness of the treatments. The conclusion of this paper could be seen in Section 5 .

\section{Model Formulation}

We assume that human population is homogeneous and closed. The total population, denoted by $N$, is classified into six classes, namely, the susceptible class $(S)$, the infected with TB only and susceptible to HIV class $\left(I_{t}\right)$, the infected with HIV only and susceptible to TB class $\left(I_{h}\right)$, the infected with TB and HIV both class $\left(I_{h t}\right)$, the infected with AIDS only and susceptible to TB class $\left(A_{h}\right)$, and the infected with TB and AIDS both class $\left(A_{h t}\right)$. We also assume that the susceptible cannot get TB and HIV infection simultaneously at the same time.

We consider the anti-TB treatment control $u_{1}$ and the ARV control $u_{2}$. The control functions $u_{1}$ and $u_{2}$ are defined on interval $\left[0, t_{f}\right]$, where $0 \leq u_{i}(t) \leq 1, t \in\left[0, t_{f}\right], i=1,2$, and $t_{f}$ denotes the end time of the controls.

We use the transmission diagram as in Figure 1 for deriving our model.
The model is as follows:

$$
\begin{aligned}
\frac{d S}{d t}= & \Lambda+u_{1} \alpha_{1} I_{t}-\beta_{t} S I_{t}-\beta_{h} S I_{h}-\delta S, \\
\frac{d I_{t}}{d t}= & \beta_{t} S I_{t}-u_{1} \alpha_{1} I_{t}-\delta I_{t}-\phi \beta_{h} I_{t} I_{h}, \\
\frac{d I_{h}}{d t}= & \beta_{h} S I_{h}+u_{1} \alpha_{2} I_{h t}-\sigma_{1} \beta_{t} I_{h} I_{t}-\left(1-u_{2}\right) \gamma_{1} I_{h} \\
& -\delta I_{h}, \\
\frac{d I_{h t}}{d t}= & \sigma_{1} \beta_{t} I_{h} I_{t}-u_{1} \alpha_{2} I_{h t}-\left(1-u_{2}\right) \gamma_{2} I_{h t}-\delta I_{h t} \\
& +\phi \beta_{h} I_{t} I_{h},
\end{aligned}
$$

$$
\begin{aligned}
\frac{d A_{h}}{d t}= & \left(1-u_{2}\right) \gamma_{1} I_{h}+u_{1} \alpha_{3} A_{h t}-\sigma_{2} \beta_{t} A_{h} I_{t} \\
& -\left(\delta+\mu_{1}\right) A_{h}, \\
\frac{d A_{h t}}{d t}= & \left(1-u_{2}\right) \gamma_{2} I_{h t}+\sigma_{2} \beta_{t} A_{h} I_{t}-u_{1} \alpha_{3} A_{h t} \\
& -\left(\delta+\mu_{2}\right) A_{h t} .
\end{aligned}
$$

The region of biological interest of model (1) is

$$
\Omega=\left\{\left(S, I_{t}, I_{h}, I_{h t}, A_{h}, A_{h t}\right) \in \mathbb{R}_{+}^{6}: 0 \leq N \leq \frac{\Lambda}{\delta}\right\},
$$

and all of the parameters used in model (1) are nonnegative. The description of the parameters is given below.

Parameters of Model (1). Consider the following:

$\Lambda$ : recruitment rate into the population.

$\delta$ : natural death rate.

$\beta_{t}$ : infection rate for TB.

$\beta_{h}$ : infection rate for HIV.

$\sigma_{1}$ : progression rate from HIV only to TB infection.

$\sigma_{2}$ : progression rate from AIDS only to TB infection.

$\phi$ : progression rate from TB only to HIV infection.

$\alpha_{1}$ : recovery rate from $\mathrm{TB}$.

$\alpha_{2}$ : recovery rate from TB of TB-HIV coinfection.

$\alpha_{3}$ : recovery rate from TB of TB-AIDS coinfection.

$\mu_{1}$ : AIDS disease induced death rate.

$\mu_{2}$ : TB-AIDS disease induced death rate.

$\gamma_{1}$ : progression rate from HIV only to AIDS infection. $\gamma_{2}:$ progression rate from TB-HIV coinfection to TBAIDS coinfection. 
Model (1) is well posed in the nonnegative region $\mathbb{R}_{+}^{6}$ because the vector field on the boundary does not point to the exterior. So, if it is given an initial condition in the region, then the solution is defined for all time $t \geq 0$ and remains in the region.

We seek to minimize the number of TB-HIV/AIDS coinfections while keeping the costs of applying anti-TB and ARV treatment controls as low as possible. We consider an optimal control problem with the objective function given by

$$
\begin{aligned}
& J\left(u_{1}, u_{2}\right) \\
& =\int_{0}^{t_{f}}\left(I_{t}+I_{h t}+A_{h}+A_{h t}+\frac{c_{1}}{2} u_{1}^{2}+\frac{c_{2}}{2} u_{2}^{2}\right) d t
\end{aligned}
$$

where $c_{1}$ and $c_{2}$ are the weighting constants for anti-TB and ARV treatment efforts, respectively. We take a quadratic form for measuring the control cost $[12,13,17]$. The terms $c_{1} u_{1}^{2}$ and $c_{2} u_{2}^{2}$ describe the cost associated with the anti-TB and ARV treatment controls, respectively. Larger values of $c_{1}$ and $c_{2}$ will imply more expensive implementation cost for anti-TB and ARV treatment efforts. that

Our goal is to find an optimal control pair $u_{1}^{*}$ and $u_{2}^{*}$ such

$$
J\left(u_{1}^{*}, u_{2}^{*}\right)=\min _{\Gamma} J\left(u_{1}, u_{2}\right)
$$

where $\Gamma=\left\{\left(u_{1}, u_{2}\right) \mid 0 \leq u_{i} \leq 1, i=1,2\right\}$.

\section{Model and Sensitivity Analysis}

Consider model (1) without the control functions $u_{1}$ and $u_{2}$. Let

$$
\begin{aligned}
R_{t} & =\frac{\Lambda \beta_{t}}{\delta^{2}} \\
R_{h} & =\frac{\Lambda \beta_{h}}{\delta\left(\gamma_{1}+\delta\right)} .
\end{aligned}
$$

The parameters $R_{t}$ and $R_{h}$ are basic reproduction ratios for TB infection and HIV infection, respectively. These ratios describe the number of secondary cases of primary case during the infectious period due to the type of infection $[18,19]$.

By setting $u_{1}=u_{2}=0$, model (1) has four equilibria (with respect to the coordinates $\left.\left(S, I_{t}, I_{h}, I_{h t}, A_{h}, A_{h t}\right)\right)$; these are as follows:

(i) The disease-free equilibrium $E_{0}=(\Lambda / \delta, 0,0,0,0,0)$. This equilibrium always exists.

(ii) The TB-endemic equilibrium $E_{t}=\left(\delta / \beta_{t},\left(\delta / \beta_{t}\right)\left(R_{t}-\right.\right.$ $1), 0,0,0,0)$. The equilibrium $E_{t}$ exists if $R_{t}>1$.

(iii) The HIV-endemic equilibrium $E_{h}=\left(\left(\gamma_{1}+\delta\right) / \beta_{h}\right.$, $\left.0,\left(\delta / \beta_{h}\right)\left(R_{h}-1\right), 0,\left(\gamma_{1} \delta / \beta_{h}\left(\delta+\mu_{1}\right)\right)\left(R_{h}-1\right), 0\right)$. The equilibrium $E_{h}$ exists if $R_{h}>1$.

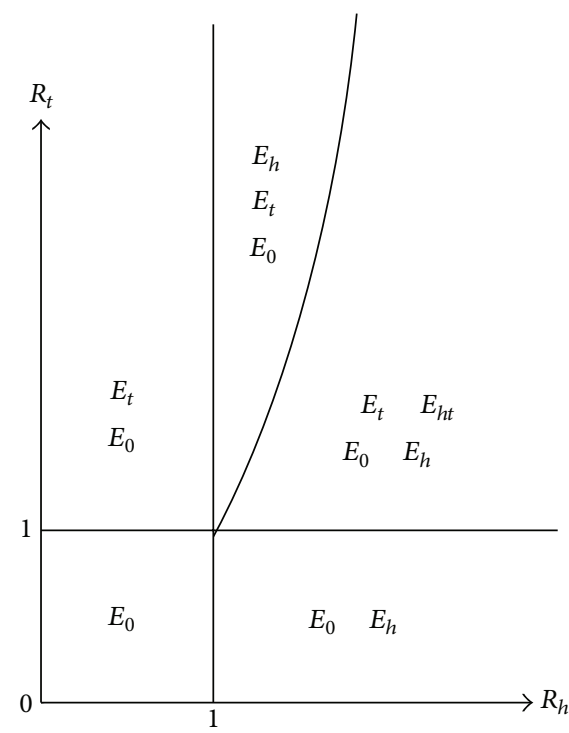

Figure 2: The diagram of equilibria with respect to $R_{h}$ and $R_{t}$.

(iv) The TB-HIV-endemic equilibrium $E_{h t}=\left(S^{*}, I_{t}^{*}, I_{h}^{*}\right.$, $\left.I_{h t}^{*}, A_{h}^{*}, A_{h t}^{*}\right)$, where

$$
\begin{aligned}
S^{*} & =\frac{\sigma_{1} \beta_{t} I_{t}^{*}+\gamma_{1}+\delta}{\beta_{h}}, \\
I_{h}^{*} & =\frac{\beta_{t}^{2} \sigma_{1} I_{t}^{*}+\delta \beta_{h}\left(R_{t} / R_{h}-1\right)}{\beta_{h}^{2}}, \\
I_{h t}^{*} & =\frac{\left(\sigma_{1} \beta_{t}+\phi \beta_{h}\right)}{\left(\gamma_{2}+\delta\right)} I_{h}^{*} I_{t}^{*}, \\
A_{h}^{*} & =\frac{\gamma_{1} I_{h}^{*}}{\sigma_{2} \beta_{t} I_{t}^{*}+\delta+\mu_{1}}, \\
A_{h t}^{*} & =\frac{\gamma_{2} I_{h t}^{*}+\sigma_{2} \beta_{t} A_{h}^{*} I_{t}^{*}}{\delta+\mu_{2}},
\end{aligned}
$$

and $I_{t}^{*}$ satisfies the quadratic equation

$$
A_{0}\left(I_{t}^{*}\right)^{2}+A_{1} I_{t}^{*}+A_{2}=0
$$

where

$$
\begin{aligned}
& A_{0}=\beta_{t}^{2} \sigma_{1}\left(\beta_{t} \sigma_{1}+\beta_{h} \phi\right) \\
& A_{1} \\
& =\frac{\delta^{3} R_{t}\left(\delta+\gamma_{1}\right)\left(\delta \sigma_{1} R_{h}(\phi-1)+2 \delta \sigma_{1} R_{t}+\phi R_{t}\left(\delta+\gamma_{1}\right)\right)}{\Lambda^{2}} \\
& A_{2}=-\frac{\delta^{2}\left(\delta+\gamma_{1}\right)^{2}\left(R_{h}-R_{t}+\phi R_{h}\left(R_{h}-1\right)\right)}{\Lambda} .
\end{aligned}
$$

The HIV-TB coinfection equilibrium $E_{h t}$ exists if $R_{h}, R_{t}>1$ and $\phi R_{h}^{2}+R_{h}(1-\phi)>R_{t}$.

Summarizing the above results, we get diagram of existence of equilibria with respect to $R_{h}$ and $R_{t}$ as in Figure 2 . The 


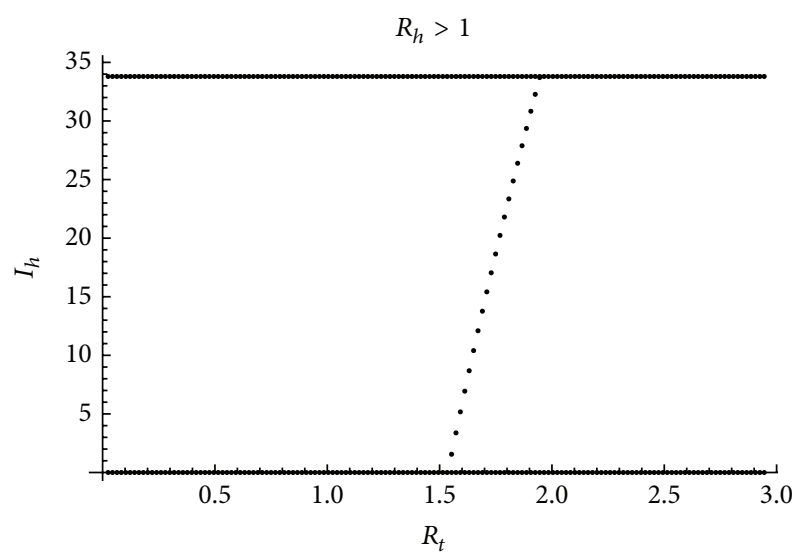

Figure 3: The bifurcation diagram for $R_{t}$ versus $I_{h}$.

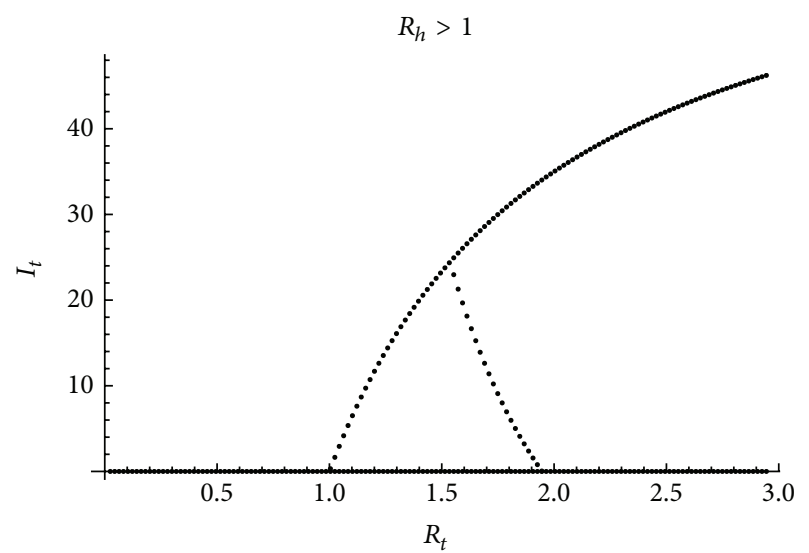

Figure 4: The bifurcation diagram for $R_{t}$ versus $I_{t}$.

numerical bifurcation diagrams for the basic reproduction numbers $R_{t}$ versus the infective classes $I_{h}, I_{t}$, and $I_{h t}$ are given in Figures 3-5, respectively. In Figures $3-5, R_{h}$ is fixed for a value larger than one.

The following theorems give the stability criteria of the equilibriums.

Theorem 1. The disease-free equilibrium $E_{0}$ is locally asymptotically stable if $R_{t}, R_{h}<1$ and unstable if $R_{t}, R_{h}>1$.

Proof. Linearizing model (1) near the equilibrium $E_{0}$ gives eigenvalues $-\delta,-\left(\gamma_{2}+\delta\right),-\left(\mu_{1}+\delta\right),-\left(\mu_{2}+\delta\right), \delta\left(R_{t}-1\right)$, and $\left(\gamma_{1}+\delta\right)\left(R_{h}-1\right)$. It is clear that all of the eigenvalues are negative if $R_{t}, R_{h}<1$. So, if $R_{t}, R_{h}<1$, the equilibrium $E_{0}$ is locally asymptotically stable. Otherwise, it is unstable.

Theorem 2. Suppose that the TB-endemic equilibrium $E_{t}$ exists. It is locally asymptotically stable if $R_{h} / R_{t}<1$; otherwise it is unstable.

Proof. Linearizing model (1) near the equilibrium $E_{t}$ gives eigenvalues $-\delta,-\left(\gamma_{2}+\delta\right),-\left(\delta+\mu_{2}\right), \delta\left(1-R_{t}\right),-\mu_{1}-\delta\left[\sigma_{2}\left(R_{t}-\right.\right.$ $1)+1]$, and $\left(R_{h} / R_{t}-1\right)\left(\delta+\gamma_{1}\right)-\delta \sigma_{1}\left(R_{t}-1\right)$. So, the equilibrium

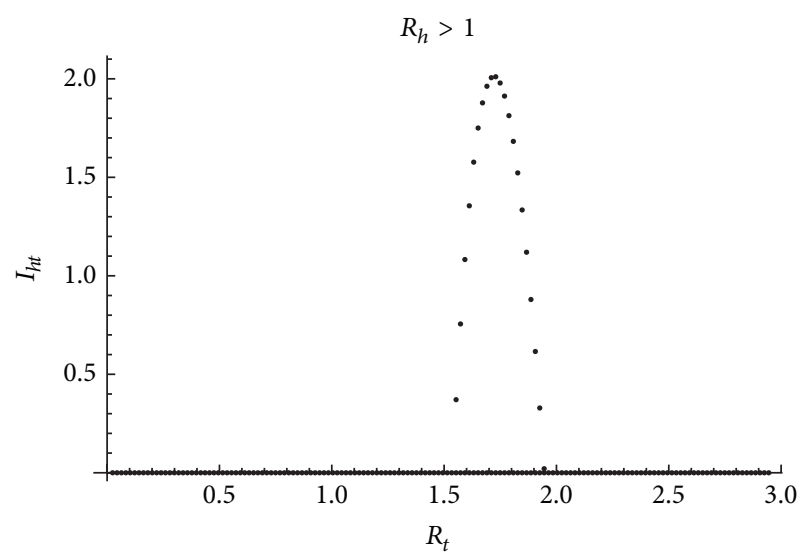

FIGURE 5: The bifurcation diagram for $R_{t}$ versus $I_{h t}$.

$E_{t}$ is locally asymptotically stable if $R_{t} / R_{h}<1$; otherwise it is unstable.

Theorem 3. Suppose that the HIV-endemic equilibrium $E_{h}$ exists. It is locally asymptotically stable if $R_{t} / R_{h}<1$; otherwise it is unstable.

Proof. Linearizing model (1) near the equilibrium $E_{h}$ gives eigenvalues $-\left(\mu_{1}+\delta\right),-\left(\mu_{2}+\delta\right),-\left(\gamma_{2}+\delta\right)$, and $\delta\left(R_{t} / R_{h}-\right.$ $\left.1-\phi\left(R_{h}-1\right)\right)$ and the roots of quadratic equation $x^{2}+\delta R_{h} x+$ $\delta\left(\delta+\gamma_{1}\right)\left(R_{h}-1\right)=0$. So, if $R_{t} / R_{h}<1$, then the equilibrium $E_{h}$ is locally asymptotically stable; otherwise it is unstable.

In the following we investigate the sensitivity of the basic reproduction numbers $R_{t}$ and $R_{h}$ to the parameters in the model. The sensitivity analysis determines the model robustness to parameter values. Here, we could know the parameters that have a high impact on the reproduction numbers $\left(R_{t}\right.$ and $\left.R_{h}\right)$. Using the approach in [20], we derived the analytical expression for sensitivity index of $R_{t}$ and $R_{h}$ to each parameter.

The normalized forward sensitivity index of a variable, $h$, that depends differentially on a parameter, $l$, is defined as

$$
\Upsilon_{l}^{h}:=\frac{\partial h}{\partial l} \frac{l}{h} .
$$

Now, using the parameter values in Table 1 , we have the following results in Table 2 . The sensitivity index of $R_{t}$ with respect to $\beta_{t}$ is

$$
\Upsilon_{\beta_{t}}^{R_{t}}:=\frac{\partial R_{t}}{\partial \beta_{t}} \frac{\beta_{t}}{R_{t}}=1
$$

The sensitivity indices of the basic reproduction numbers $\left(R_{t}\right.$ and $R_{h}$ ) to parameters (see Table 2), such as recruitment rate of the population $(\Lambda)$, natural death rate $(\delta)$, infection rate for HIV $\left(\beta_{h}\right)$, and progression rate from HIV only to AIDS infection $\left(\gamma_{1}\right)$, can be derived in the same way as (10). In the sensitivity indices of $R_{t}$, since $Y_{\beta_{t}}^{R_{t}}=1$, increasing (or decreasing) infection rate for $\mathrm{TB}, \beta_{t}$, by $10 \%$, increases (or decreases) the reproduction number $R_{t}$ by $10 \%$. In the 
same way, increasing (or decreasing) recruitment rate of the population $\Lambda$ by $10 \%$ increases (or decreases) $R_{t}$ by $10 \%$ and in like manner, increasing (or decreasing) natural death rate $\delta$ by $10 \%$ decreases (increases) $R_{t}$ by $20 \%$.

Similarly, for the sensitivity indices of $R_{h}$, since $\Upsilon_{\beta_{h}}^{R_{h}}=$ 1 , increasing (or decreasing) infection rate for HIV, $\beta_{h}$, by $10 \%$, increases (or decreases) the reproduction number $R_{h}$ by $10 \%$. Thus, increasing (or decreasing) recruitment rate of the population $\Lambda$, by $10 \%$, increases (or decreases) $R_{h}$ by $10 \%$. Also increasing (or decreasing) natural death rate $\delta$ by $10 \%$ decreases (increases) $R_{h}$ by $16,67 \%$. In a similar manner, increasing (or decreasing) progression rate from HIV only to AIDS infection $\gamma_{1}$ by $10 \%$ decreases (increases) $R_{h}$ by $3,33 \%$.

\section{Analysis of Optimal Control}

Next, we analyze model (1) with its control functions $u_{1}$ and $u_{2}$. Consider the objective function (3) for model (1). The necessary conditions to determine the optimal controls $u_{1}^{*}$ and $u_{2}^{*}$ such as condition (4) with constraint model (1) could be obtained using the Pontryagin Maximum Principle [21]. The principle converts (1)-(4) into minimizing Hamiltonian function $H$ problem with respect to $\left(u_{1}, u_{2}\right)$; that is,

$$
\begin{aligned}
H & \left(S, I_{t}, I_{h}, I_{h t}, A_{h}, A_{h t}, u_{1}, u_{2}, \lambda_{1}, \lambda_{2}, \ldots, \lambda_{6}\right) \\
& =I_{t}+I_{h t}+A_{h}+A_{h t}+\frac{c_{1}}{2} u_{1}^{2}+\frac{c_{2}}{2} u_{2}^{2}+\sum_{i=1}^{6} \lambda_{i} g_{i},
\end{aligned}
$$

where $g_{i}$ denotes the right hand side of model (1) which is the $i$ th state variable equation. The variables $\lambda_{i}, i=1,2, \ldots, 6$, are called adjoint variables satisfying the following costate equations:

$$
\begin{aligned}
\frac{d \lambda_{1}}{d t}= & \left(\lambda_{1}-\lambda_{2}\right) \beta_{t} I_{t}+\left(\lambda_{1}-\lambda_{3}\right) \beta_{h} I_{h}+\lambda_{1} \delta \\
\frac{d \lambda_{2}}{d t}= & -1+\left(\lambda_{2}-\lambda_{1}\right) u_{1} \alpha_{1}+\left(\lambda_{1}-\lambda_{2}\right) \beta_{t} S+\lambda_{2} \delta \\
& +\left(\lambda_{3}-\lambda_{4}\right) \sigma_{1} \beta_{t} I_{h}+\left(\lambda_{2}-\lambda_{4}\right) \phi \beta_{h} I_{h} \\
& +\left(\lambda_{5}-\lambda_{6}\right) \sigma_{2} \beta_{t} A_{h}, \\
\frac{d \lambda_{3}}{d t}= & \left(\lambda_{1}-\lambda_{3}\right) \beta_{h} S+\left(\lambda_{2}-\lambda_{4}\right) \phi \beta_{h} I_{t} \\
& +\left(\lambda_{3}-\lambda_{4}\right) \sigma_{1} \beta_{t} I_{t}+\left(\lambda_{3}-\lambda_{5}\right)\left(1-u_{2}\right) \gamma_{1} \\
& +\lambda_{3} \delta, \\
\frac{d \lambda_{4}}{d t}= & -1+\left(\lambda_{4}-\lambda_{3}\right) \alpha_{2} u_{1}+\left(\lambda_{4}-\lambda_{6}\right)\left(1-u_{2}\right) \gamma_{2} \\
& +\lambda_{4} \delta, \\
\frac{d \lambda_{5}}{d t}= & -1+\left(\lambda_{5}-\lambda_{6}\right) \sigma_{2} \beta_{t} I_{t}+\lambda_{5}\left(\delta+\mu_{1}\right), \\
\frac{d \lambda_{6}}{d t}= & -1+\left(\lambda_{6}-\lambda_{5}\right) u_{1} \alpha_{3}+\lambda_{6}\left(\delta+\mu_{2}\right),
\end{aligned}
$$

where the transversality conditions $\lambda_{i}\left(t_{f}\right)=0, i=1, \ldots, 6$.

By applying Pontryagin's Maximum Principle and the existence result for the optimal control pairs, the steps to obtain the optimal controls $u=\left(u_{1}^{*}, u_{2}^{*}\right)$ are as follows $[22,23]$ :

(1) Minimize the Hamilton function $H$ with respect to $u$; that is, $\partial H / \partial u=0$, which is the stationary condition. We obtain

$$
\begin{aligned}
& u_{1}^{*}= \begin{cases}0 & \text { for } u_{1} \leq 0 \\
\frac{\left(\lambda_{4}-\lambda_{3}\right) \alpha_{2} I_{h t}+\left(\lambda_{2}-\lambda_{1}\right) \alpha_{1} I_{t}+\left(\lambda_{6}-\lambda_{5}\right) \alpha_{3} A_{h t}}{c_{1}} & \text { for } 0<u_{1}<1 \\
1 & \text { for } u_{1} \geq 1,\end{cases} \\
& u_{2}^{*}= \begin{cases}0 & \text { for } u_{2} \leq 0 \\
\frac{\left(\lambda_{6}-\lambda_{4}\right) \gamma_{2} I_{h t}+\left(\lambda_{5}-\lambda_{3}\right) \gamma_{1} I_{h}}{c_{2}} & \text { for } 0<u_{2}<1 \\
1 & \text { for } u_{2} \geq 1 .\end{cases}
\end{aligned}
$$

(2) Solve the state system $\dot{x}(t)=\partial H / \partial \lambda$ which is model (1), where $x=\left(S, I_{t}, I_{h}, I_{h t}, A_{h}, A_{h t}\right), \lambda=\left(\lambda_{1}, \lambda_{2}\right.$, $\left.\ldots, \lambda_{6}\right)$ with initial condition $x(0)$.

(3) Solve the costate system $\dot{\lambda}(t)=-\partial H / \partial x$ which is system (12) with the end condition $\lambda_{i}\left(t_{f}\right)=0, i=$ $1, \ldots, 6$.

Hence, we obtain the following theorem.
Theorem 4. The optimal controls $\left(u_{1}^{*}, u_{2}^{*}\right)$ that minimize the objective function $J\left(u_{1}, u_{2}\right)$ on $\Gamma$ are given by

$$
\begin{aligned}
u_{1}^{*} & =\max \{0, \\
& \left.\min \left(1, \frac{\left(\lambda_{4}-\lambda_{3}\right) \alpha_{2} I_{h t}+\left(\lambda_{2}-\lambda_{1}\right) \alpha_{1} I_{t}+\left(\lambda_{6}-\lambda_{5}\right) \alpha_{3} A_{h t}}{c_{1}}\right)\right\}, \\
u_{2}^{*} & =\max \left\{0, \min \left(1, \frac{\left(\lambda_{6}-\lambda_{4}\right) \gamma_{2} I_{h t}+\left(\lambda_{5}-\lambda_{3}\right) \gamma_{1} I_{h}}{c_{2}}\right)\right\},
\end{aligned}
$$


TABLE 1: Parameter values.

\begin{tabular}{|c|c|c|c|c|c|}
\hline Parameter & Value & Reference & Parameter & Value & Reference \\
\hline$\Lambda$ & 50000/year & [7] & $\alpha_{1}$ & 2/year & Assumed \\
\hline$\delta$ & 0.02/year & [7] & $\alpha_{2}$ & $1.2 /$ year & Assumed \\
\hline$\beta_{t}$ & 0.00031/year & Assumed & $\alpha_{3}$ & 1/year & Assumed \\
\hline$\beta_{h}$ & $0.00045 /$ year & Assumed & $\mu_{1}$ & $0.03 /$ year & Assumed \\
\hline$\sigma_{1}$ & $1.02 /$ year & Assumed & $\mu_{2}$ & $0.06 /$ year & Assumed \\
\hline$\sigma_{2}$ & 1.04/year & Assumed & $\gamma_{1}$ & 0.01/year & Assumed \\
\hline$\phi$ & $1.0002 /$ year & Assumed & $\gamma_{2}$ & $0.05 /$ year & Assumed \\
\hline
\end{tabular}

TABLE 2: Sensitivity indices to parameter for the TB-HIV model.

\begin{tabular}{lccc}
\hline Parameter & $\begin{array}{l}\text { Sensitivity } \\
\text { index }\left(R_{t}\right)\end{array}$ & Parameter & $\begin{array}{c}\text { Sensitivity } \\
\text { index }\left(R_{h}\right)\end{array}$ \\
\hline$\Lambda$ & 1 & $\Lambda$ & 1 \\
$\beta_{t}$ & 1 & $\beta_{h}$ & 1 \\
$\delta$ & -2 & $\delta$ & -1.667 \\
& & $\gamma_{1}$ & -0.333 \\
\hline
\end{tabular}

where $\lambda_{i}, i=1, \ldots, 6$, is the solution of the costate equations (12) with the transversality conditions $\lambda_{i}\left(t_{f}\right)=0, i=1, \ldots, 6$.

Substituting the optimal controls $\left(u_{1}^{*}, u_{2}^{*}\right)$ which are obtained from the state system (1) and the costate system (12), we obtain the optimal system. The solutions of the optimality system will be solved numerically for some parameter choices. Most of the parameter values are assumed within realistic ranges for a typical scenario due to lack of data.

\section{Numerical Simulation}

In this section, we investigate the numerical simulations of model (1) with and without optimal control. The optimal control strategy is obtained by the iterative method of RungeKutta method of order 4 [24]. We start to solve the state equations by the forward Runge-Kutta method of order 4 . Then we use the backward Runge-Kutta method of order 4 to solve the costate equations with the terminal conditions. Then, the controls are updated by using a convex combination of the previous controls and the value from the characterizations of $u_{1}^{*}$ and $u_{2}^{*}$. This process is repeated and iteration is stopped if the values of unknowns at the previous iteration are very close to the ones at the present iteration.

We consider three scenarios. In the first scenario, we consider only the anti-TB treatment control. In the second scenario, we consider only the ARV treatment control. In the last one, we use the optimal anti-TB and ARV treatment controls. Parameters used in these simulations are given in Table 1. In these simulations, we use initial condition $\left(S(0), I_{t}(0), I_{h}(0), I_{h t}(0), A_{h}(0), A_{h t}(0)\right)=(500,50,10,5,5,5)$ and weighting constants $c_{1}=80, c_{2}=100$.

5.1. First Scenario. In this scenario, we set the ARV control $u_{2}$ to zero and activate only the anti-TB treatment control $u_{1}$. The profile of the optimal treatment control $u_{1}^{*}$ for

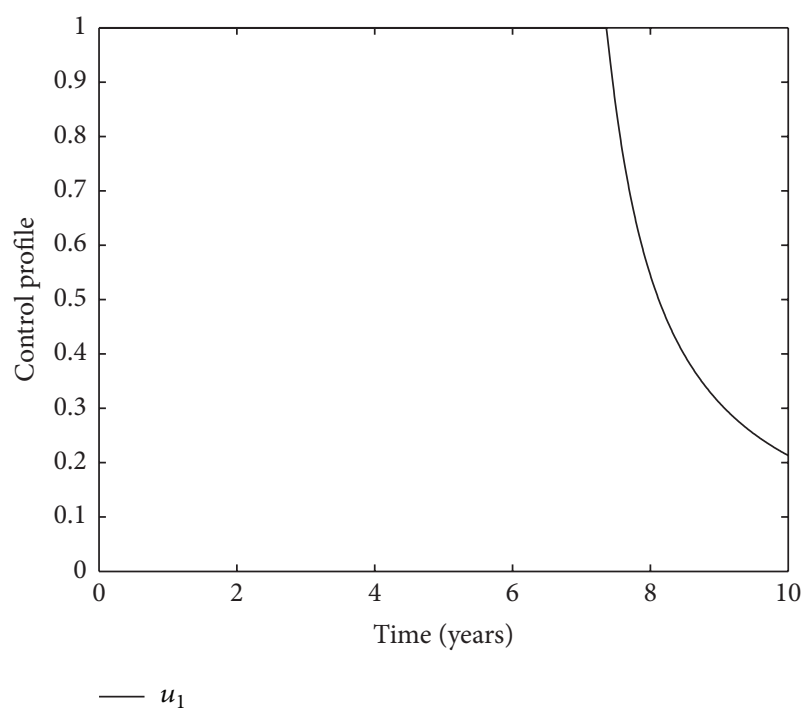

FIgURE 6: The profile of the optimal anti-TB control $u_{1}^{*}$.

this scenario could be seen in Figure 6. To eliminate TBHIV/AIDS coinfection in 10 years, the anti-TB treatment should be given intensively almost 7.5 years before decreasing to the lower bound in the end of 10th year.

The dynamics of the infected populations of this scenario are given in Figures 7 and 8. We observe in Figure 7 that this control strategy results in a significant decrease in the number of TB infected $\left(I_{t}\right)$ and TB-HIV coinfection $\left(I_{h t}\right)$ populations compared with the case without control. Specifically, using the control strategy, the TB-HIV coinfection population start to decrease from the third year. Also in the right of Figure 8, this control strategy results in a significant decrease in the number of TB-AIDS coinfections $\left(A_{h t}\right)$ as against an increase in the uncontrolled case. On the contrary, the result in the left of Figure 8 shows that the number of AIDS infected $\left(A_{h}\right)$ populations with and without the control does not differ significantly because there is no intervention against AIDS infection. Hence, the anti-TB treatment control gives a significant effect in controlling infected TB and also TBHIV/AIDS coinfection.

5.2. Second Scenario. In the second scenario, we set the antiTB treatment control $u_{1}$ to zero and activate only the ARV treatment control $u_{2}$. The control profile of ARV treatment is shown in Figure 9. We see that, to eliminate TB-HIV/AIDS 

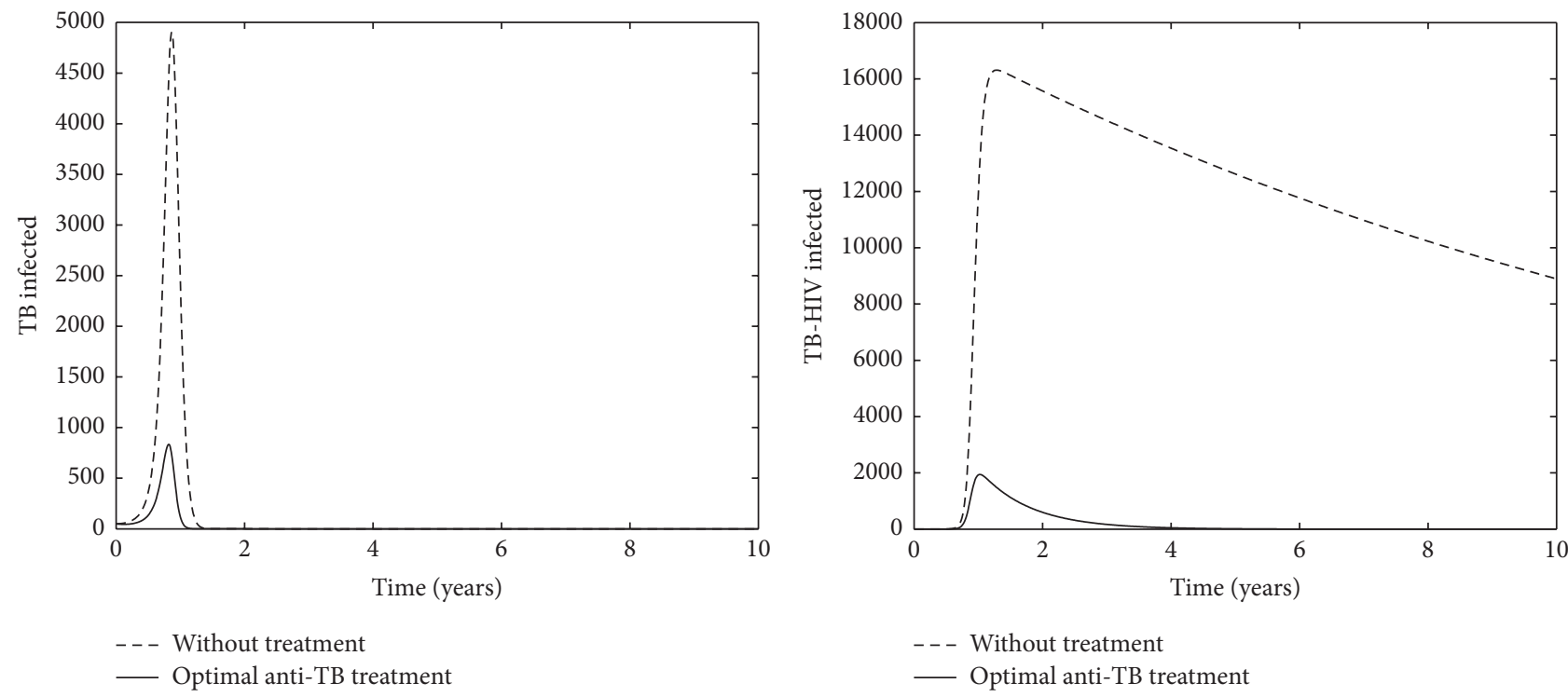

Figure 7: The dynamics of $I_{t}$ and $I_{h t}$ using control $u_{1}^{*}$.
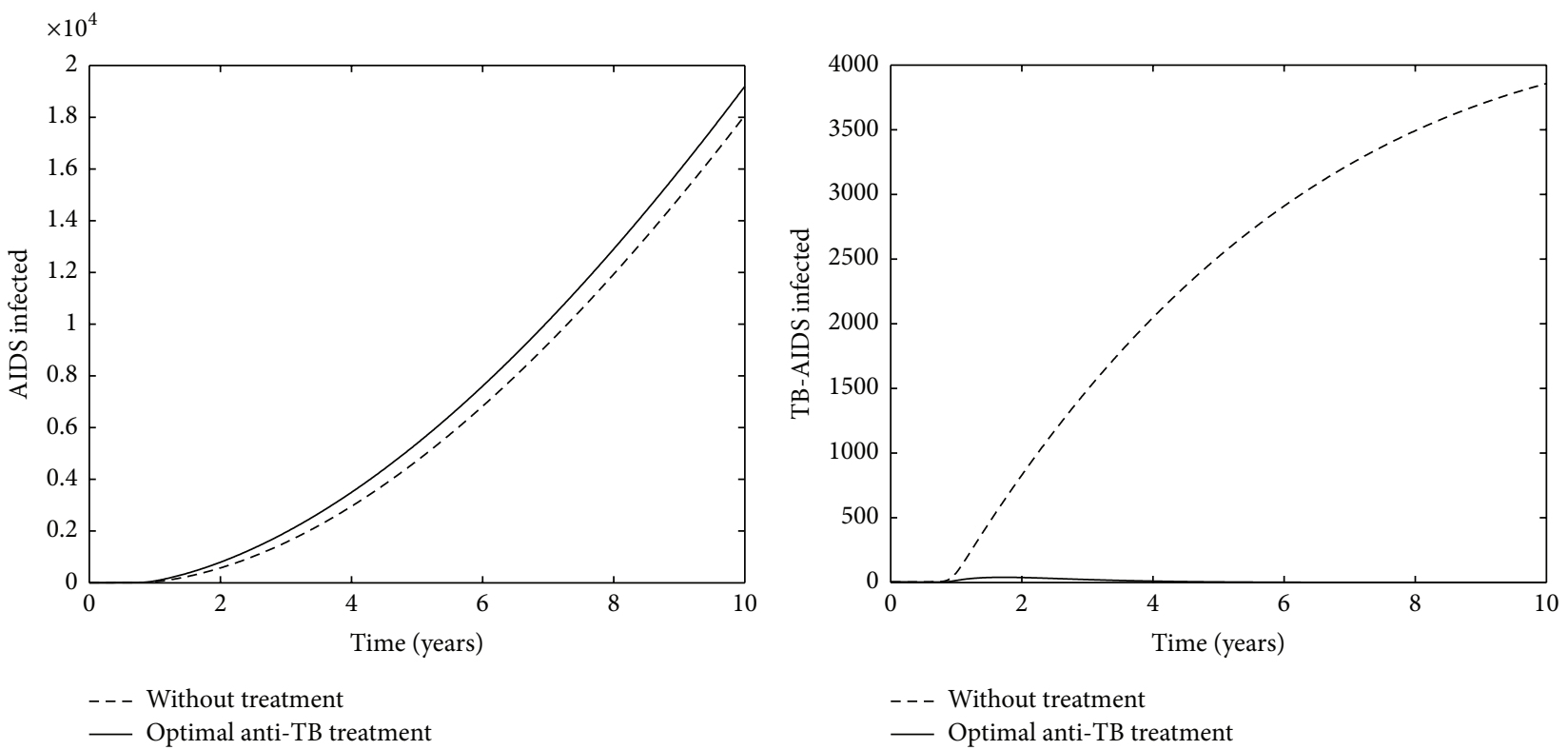

FIgURE 8: The dynamics of $A_{h}$ and $A_{h t}$ using control $u_{1}^{*}$.

coinfection in 10 years, the ARV treatment should be given intensively during 10 years.

The dynamics of the TB-HIV/AIDS coinfection of this scenario are given in Figures 10 and 11. We observe in Figure 10 that there is no significant difference in the number of TB infected populations with and without the ARV control treatment only. This may be due to the absence of the treatment against TB infection. It was also observed that the number of TB-HIV coinfection populations increases with this control strategy compared to the number without control. The positive impact of this strategy is shown in Figure 11, where the number of the AIDS infected and the TB-AIDS coinfection populations decreases significantly at the end of the intervention period.

5.3. Third Scenario. In this scenario, we consider the anti-TB and ARV treatment controls simultaneously. The profile of the optimal anti-TB treatment control $u_{1}^{*}$ and ARV control $u_{2}^{*}$ of this scenario is in Figure 12. To eliminate TB-HIV/AIDS coinfection in 10 years, the anti-TB treatment should be given 


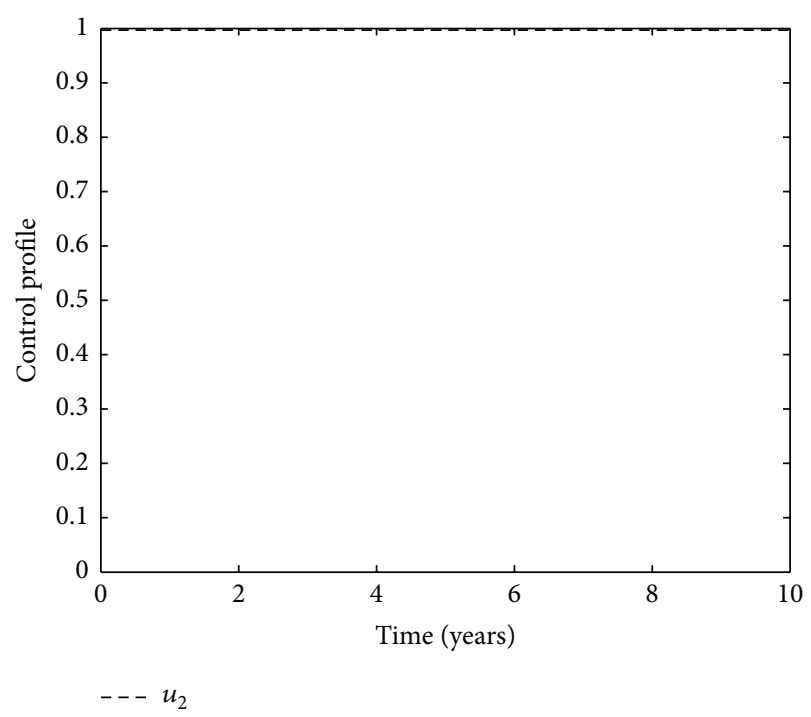

FIGURE 9: The profile of the optimal ARV control $u_{2}^{*}$.
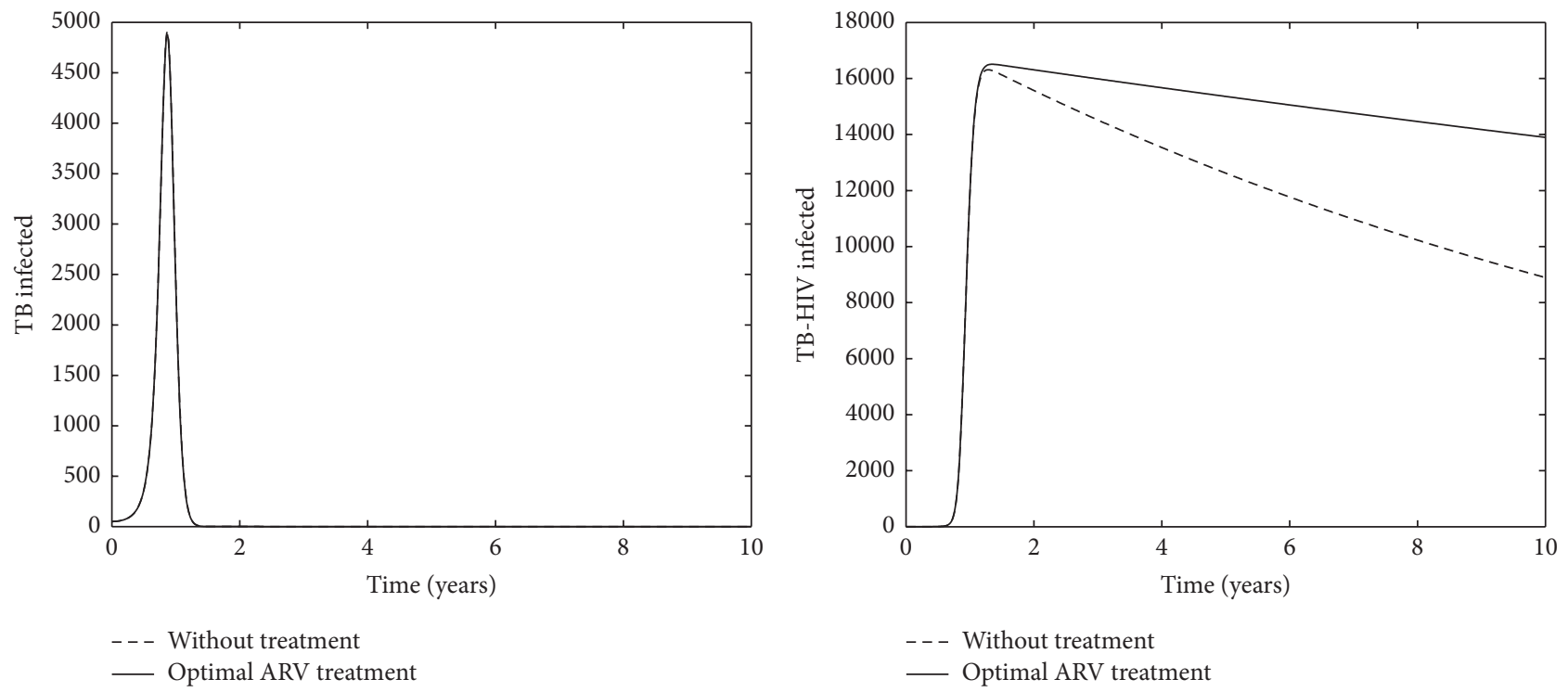

FIGURE 10: The dynamics of $I_{t}$ and $I_{h t}$ using control $u_{2}^{*}$.

intensively almost 8 years before dropping gradually until reaching the lower bound in the end of 10th year, and the ARV treatment is also given similar to anti-TB treatment, except at the beginning of the treatment.

Using the optimal controls in Figure 12, the dynamics of the TB-HIV/AIDS coinfection populations are given in Figures 13 and 14, respectively. For this strategy, we observed in Figure 13 that the control strategies resulted in a decrease in the number of $\mathrm{TB}$ infected and TB-HIV coinfection populations compared to the number without control. A similar decrease is observed in Figure 14 for AIDS infected and TB-AIDS coinfection populations in the control strategy, while an increased number for the uncontrolled case resulted.
Our numerical results show that the combination of antiTB treatment and ARV treatment has the highest impact to diminish the size of TB-HIV/AIDS coinfection. When using only one control, the anti-TB treatment is more effective than ARV treatment to reduce the number of TB-HIV/AIDS coinfection populations.

\section{Conclusion}

In this paper, we have studied a deterministic model for the transmission of TB-HIV coinfection that includes use of antiTB and ARV treatment as optimal control strategies. The model without controls exhibits four equilibria, namely, the 

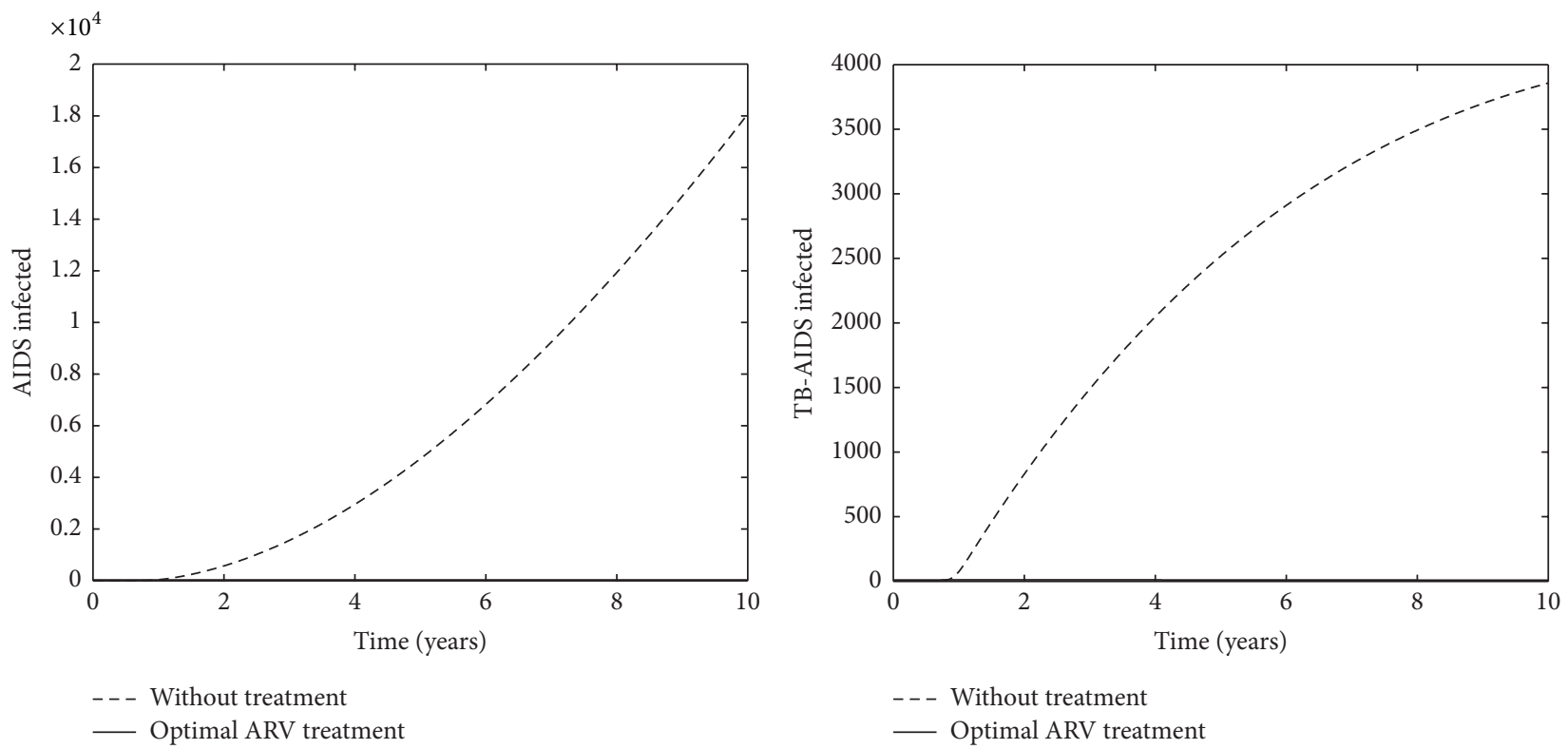

Figure 11: The dynamics of $A_{h}$ and $A_{h t}$ using control $u_{2}^{*}$.

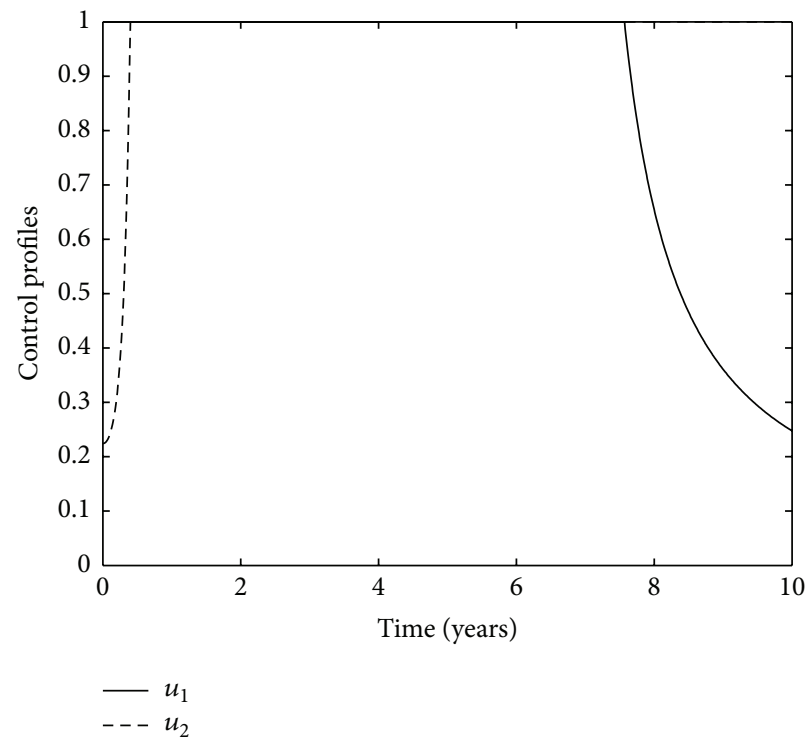

FIGURE 12: The profile of the optimal controls $u_{1}^{*}$ and $u_{2}^{*}$.

disease-free equilibrium, the HIV-free equilibrium, the TBfree equilibrium, and the endemic equilibrium. We further obtain two thresholds, $R_{t}$ and $R_{h}$, which are basic reproduction ratios for TB and HIV infections, respectively. These ratios determine the existence and stability of the equilibria of the model. The existence of the equilibria with respect to the thresholds $R_{t}$ and $R_{h}$ is summarized in Figure 2. If both the thresholds are less than unity then the diseases-free equilibrium is locally asymptotically stable. But if $R_{t}$ is greater than unity with the condition $R_{t}>R_{h}$ and $R_{h}$ is greater than unity with the condition $R_{h}>R_{t}$, then the HIV-free and TB-free equilibriums are locally asymptotically stable, respectively. Finally, the optimal control theory for TB-HIV coinfection model is derived analytically by applying the Pontryagin Maximum Principle. The numerical simulations were carried out to perform the optimal anti-TB and ARV treatment controls. From our analysis and numerical results, we conclude that the combination of anti-TB and ARV treatments is the most effective to reduce the TB-HIV coinfection. However, if we have to use only one control, then the anti-TB treatment 

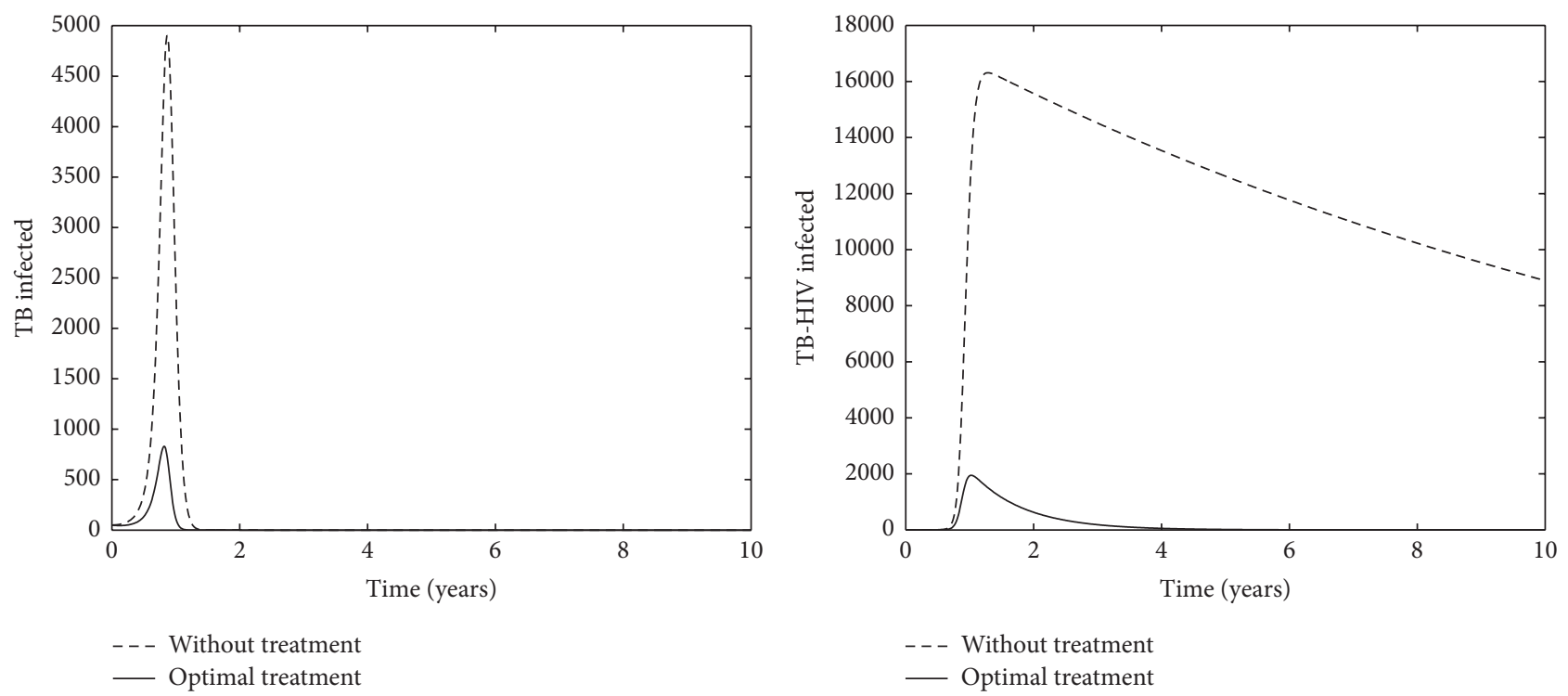

Figure 13: The dynamics of $I_{t}$ and $I_{h t}$ using controls $u_{1}^{*}$ and $u_{2}^{*}$.
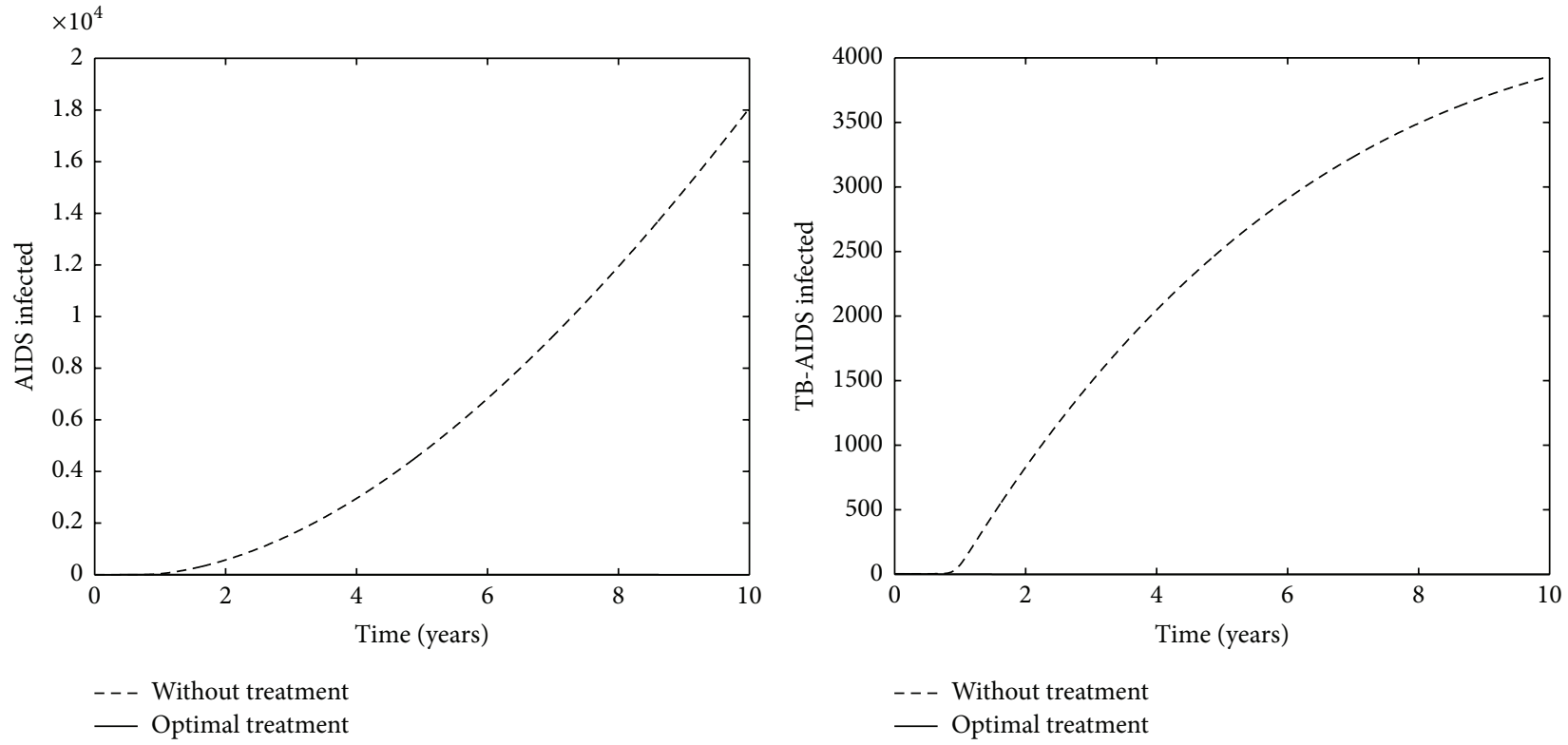

FIgURE 14: The dynamics of $A_{h}$ and $A_{h t}$ using controls $u_{1}^{*}$ and $u_{2}^{*}$.

is better than ARV treatment to eliminate the number of TBHIV/AIDS coinfection populations.

\section{Competing Interests}

The authors declare that there are no competing interests regarding the publication of this paper.

\section{Acknowledgments}

Parts of this research are funded by the Indonesian Directorate General for Higher Education (DIKTI) through DIPA
Universitas Airlangga/BOPTN 2014 according to SK Rektor no. $965 / \mathrm{UN} 3 / 2014$.

\section{References}

[1] WHO, Factsheet on the World Tuberculosis Report 2013, WHO, Geneva, Switzerland, 2013.

[2] http://www.cdc.gov/tb/statistics.

[3] http://www.who.int/mediacentre.

[4] S. Gakkhar and N. Chavda, "A dynamical model for HIV-TB coinfection," Applied Mathematics and Computation, vol. 218, no. 18, pp. 9261-9270, 2012. 
[5] R. Naresh, D. Sharma, and A. Tripathi, "Modelling the effect of tuberculosis on the spread of HIV infection in a population with density-dependent birth and death rate," Mathematical and Computer Modelling, vol. 50, no. 7-8, pp. 1154-1166, 2009.

[6] L. W. Roeger, Z. Feng, and C. Castillo-Chavez, "Modeling TB and HIV co-infections," Mathematical Biosciences and Engineering, vol. 6, no. 4, pp. 815-837, 2009.

[7] O. Sharomi, C. N. Podder, A. B. Gumel, and B. Song, "Mathematical analysis of the transmission dynamics of HIV/TB coinfection in the presence of treatment," Mathematical Biosciences and Engineering, vol. 5, no. 1, pp. 145-174, 2008.

[8] Ahmadin and Fatmawati, "Mathematical modeling of drug resistance in tuberculosis transmission and optimal control treatment," Applied Mathematical Sciences, vol. 8, no. 92, pp. 4547-4559, 2014.

[9] F. B. Agusto, "Optimal chemoprophylaxis and treatment control strategies of a tuberculosis transmission model," World Journal of Modelling and Simulation, vol. 5, no. 3, pp. 163-173, 2009.

[10] S. Bowong and A. M. A. Alaoui, "Optimal intervention strategies for tuberculosis," Communications in Nonlinear Science and Numerical Simulation, vol. 18, no. 6, pp. 1441-1453, 2013.

[11] Fatmawati and H. Tasman, "An optimal control strategy to reduce the spread of malaria resistance," Mathematical Biosciences, vol. 262, pp. 73-79, 2015.

[12] O. D. Makinde and K. O. Okosun, "Impact of chemo-therapy on optimal control of malaria disease with infected immigrants," Biosystems, vol. 104, no. 1, pp. 32-41, 2011.

[13] K. O. Okosun, O. D. Makinde, and I. Takaidza, "Impact of optimal control on the treatment of HIV/AIDS and screening of unaware infectives," Applied Mathematical Modelling, vol. 37, no. 6, pp. 3802-3820, 2013.

[14] K. O. Okosun and O. D. Makinde, "A co-infection model of malaria and cholera diseases with optimal control," Mathematical Biosciences, vol. 258, pp. 19-32, 2014.

[15] K. O. Okosun and O. D. Makinde, "Optimal control analysis of hepatitis $\mathrm{C}$ virus with acute and chronic stages in the presence of treatment and infected immigrants," International Journal of Biomathematics, vol. 7, no. 2, Article ID 1450019, 1450019, 23 pages, 2014.

[16] B. Seidu, O. D. Makinde, and I. Y. Seini, "Mathematical analysis of the effects of HIV-Malaria co-infection on workplace productivity," Acta Biotheoretica, vol. 63, no. 2, pp. 151-182, 2015.

[17] F. B. Agusto and A. I. Adekunle, "Optimal control of a twostrain tuberculosis-HIV/AIDS co-infection model," BioSystems, vol. 119, no. 1, pp. 20-44, 2014.

[18] O. Diekmann, J. A. P. Heesterbeek, and J. A. J. Metz, "On the definition and the computation of the basic reproduction ratio $R_{0}$ in models for infectious diseases in heterogenous populations," Journal of Mathematical Biology, vol. 28, no. 4, pp. 362$382,1990$.

[19] O. Diekmann and J. A. P. Heesterbeek, Mathematical Epidemiology of Infectious Diseases, Model Building, Analysis and Interpretation, John Wiley \& Sons, 2000.

[20] N. Chitnis, J. M. Hyman, and J. M. Cushing, "Determining important parameters in the spread of malaria through the sensitivity analysis of a mathematical model," Bulletin of Mathematical Biology, vol. 70, no. 5, pp. 1272-1296, 2008.

[21] L. S. Pontryagin, V. G. Boltyanskii, R. V. Gamkrelidze, and E. F. Mishchenko, The Mathematical Theory of Optimal Processes, John Wiley \& Sons, New York, NY, USA, 1962.
[22] F. L. Lewis and V. L. Syrmos, Optimal Control, John Wiley \& Sons, New York, NY, USA, 1995.

[23] D. S. Naidu, Optimal Control Systems, CRC Press, New York, NY, USA, 2002.

[24] S. Lenhart and J. T. Workman, Optimal Control Applied to Biological Models, Chapman \& Hall, New York, NY, USA, 2007. 


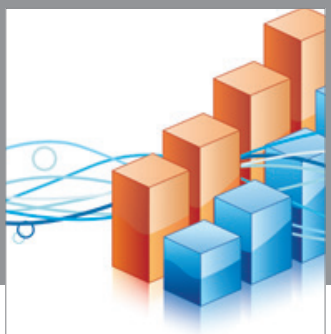

Advances in

Operations Research

vatem alat4

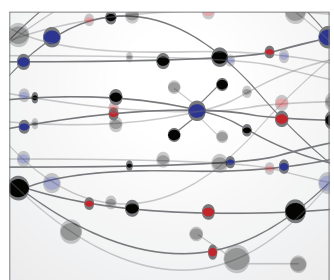

\section{The Scientific} World Journal
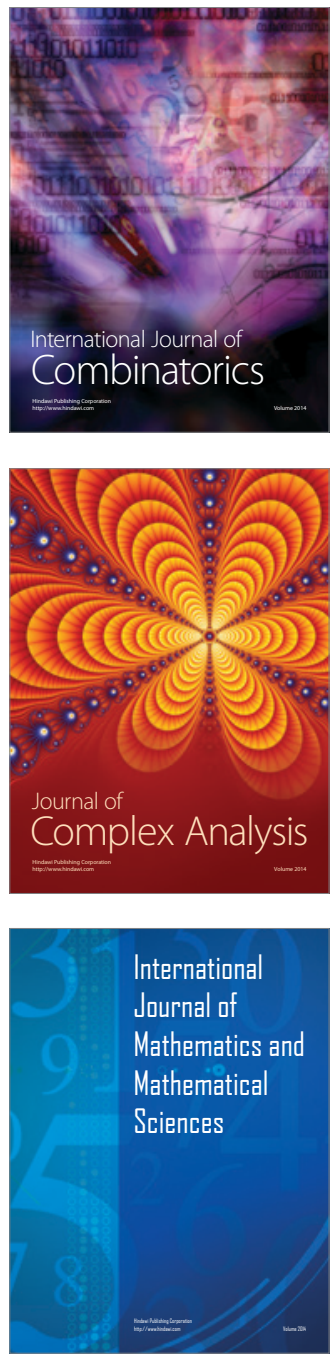
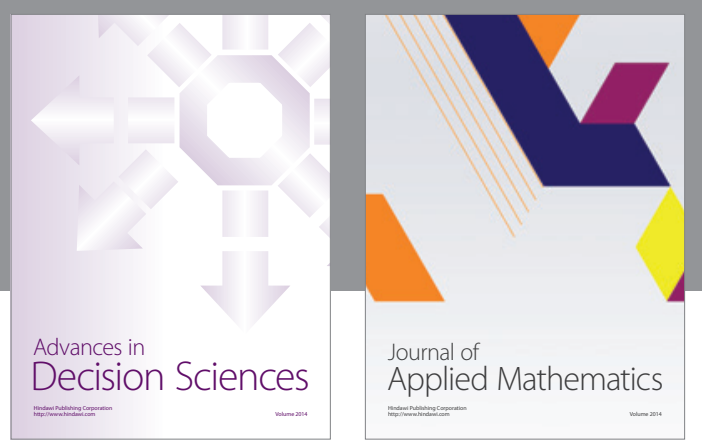

Algebra

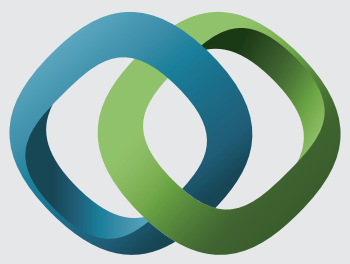

\section{Hindawi}

Submit your manuscripts at

http://www.hindawi.com
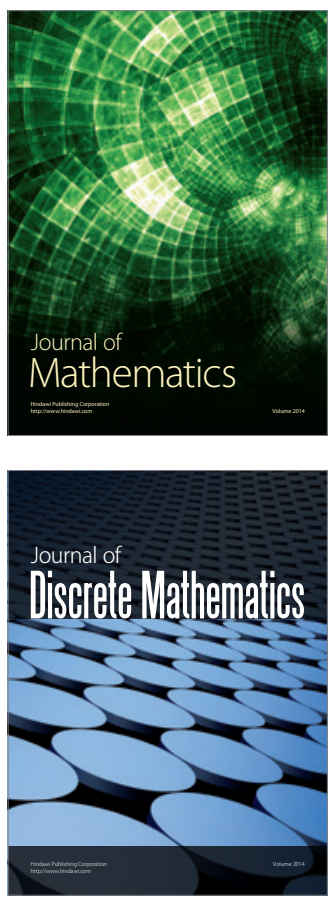

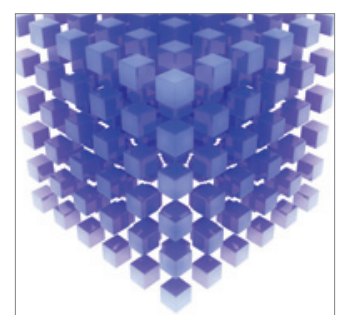

Mathematical Problems in Engineering
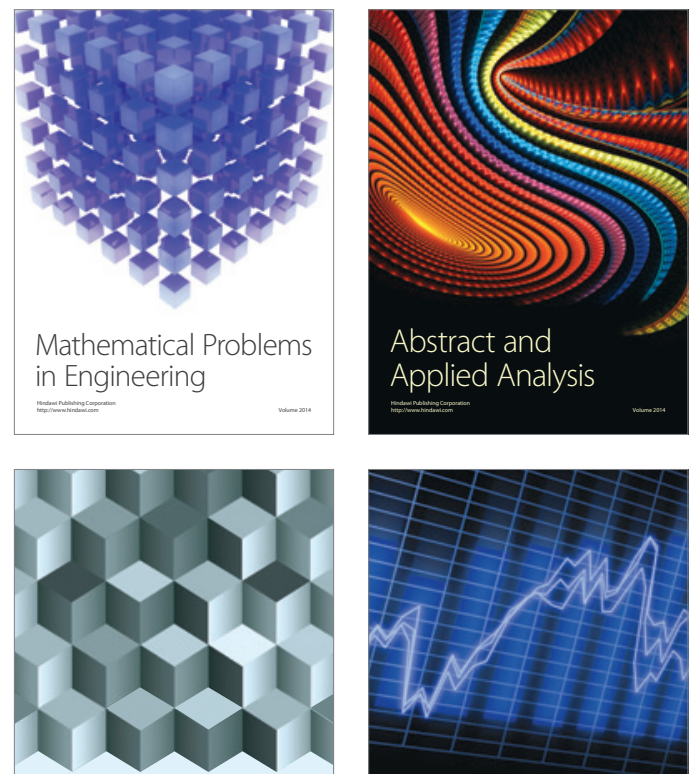

Journal of

Function Spaces

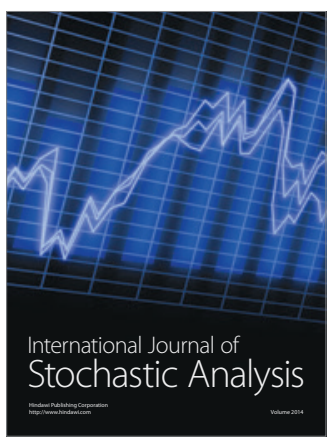

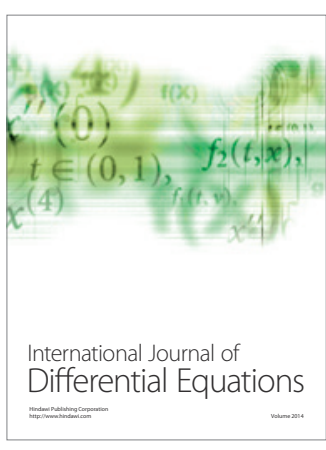
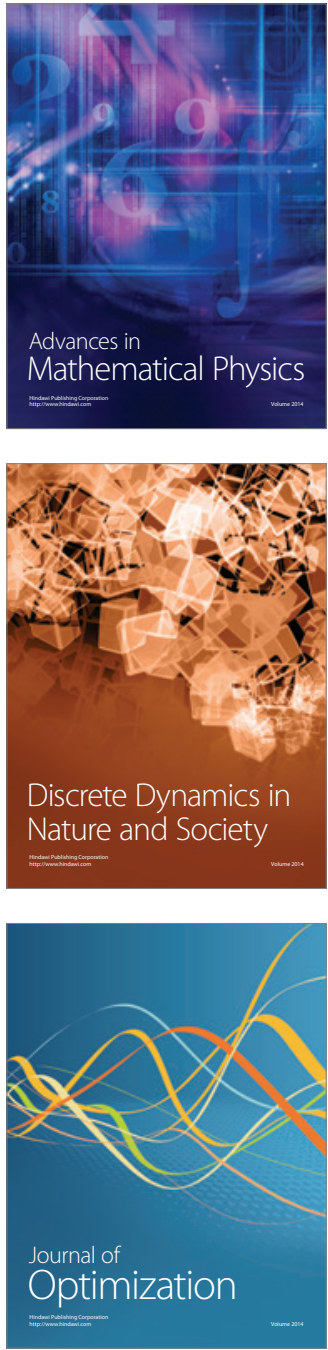